\title{
Aplicação do processo de enfermagem na assistência ao paciente com COVID-19
}

\author{
Application of the nursing process in the care of patients with COVID-19 \\ Aplicación del proceso de enfermería en el cuidado de pacientes con COVID-19
}

Ana Luiza Oliveira da Silva ORCID: https://orcid.org/0000-0002-5158-366X Universidade Tiradentes, Brasil E-mail: aninha.oliveira17@outlook.com Beatriz Almeida Santos ORCID: https://orcid.org/0000-0002-4913-3854 Universidade Tiradentes, Brasil

E-mail: beatrizalmeidasantos125@gmail.com Liliane Maria da Silva

ORCID: https://orcid.org/0000-0001-6839-8789 Universidade Tiradentes, Brasil E-mail: silvams.lili@gmail.com

Daniela Soares Rocha

ORCID: https://orcid.org/0000-0002-0385-9377 Universidade Tiradentes, Brasil E-mail: danirochadsr@outlook.com

Riviane Moura Costa Santos ORCID: https://orcid.org/0000-0002-7970-3774 Universidade Tiradentes, Brasil

E-mail: rivianemoura@hotmail.com

Geisa Carla de Brito Bezerra Lima ORCID: https://orcid.org/0000-0002-1192-3201 Universidade Tiradentes, Brasil

E-mail: geisacarlalima@hotmail.com

Fernanda Costa Martins Gallotti ORCID: https://orcid.org/0000-0002-9063-1273

Universidade Tiradentes, Brasil

E-mail: fercosmart@gmail.com

Ianka Heloisa Alencar Santos

ORCID: https://orcid.org/0000-0002-2057-0727

Universidade Tiradentes, Brasil

E-mail: iankaheloisa@outlook.com

Thandara Rejane Santos Ferreira Andrade ORCID: https://orcid.org/0000-0002-3385-7727

Universidade Tiradentes, Brasil

E-mail: thandara456@outlook.com

Yasmim Anayr Costa Ferrari ORCID: https://orcid.org/0000-0003-1766-341X Universidade Tiradentes, Brasil E-mail: yasmimanayr@hotmail.com

Carla Viviane Freitas de Jesus ORCID: https://orcid.org/0000-0002-7775-6610 Universidade Tiradentes, Brasil E-mail: carlavfj@gmail.com

Rebecca Maria Oliveira de Góis ORCID: https://orcid.org/0000-0002-3935-5904 Universidade Tiradentes, Brasil E-mail: rebecca.gois@hotmail.com

Manuela de Carvalho Vieira Martins ORCID: https://orcid.org/0000-0003-1222-5955 Universidade Tiradentes, Brasil

E-mail: manuela.cvm@hotmail.com

\section{Resumo}

Objetivo: O novo coronavírus (COVID-19) pertence a uma família de vírus que apresenta uma alta capacidade de mutação em animais. O SARS-CoV-2 segue o padrão dos indivíduos mais vulneráveis, como idosos e adultos com doenças crônicas, tendo o menor número de vítima, crianças. O presente estudo teve como objetivos identificar os possíveis diagnósticos de enfermagem e apresentar um plano de cuidados, por meio da aplicação do processo de 
enfermagem, aos pacientes que apresentam manifestações leves e graves da COVID-19, utilizando a taxonomia NANDA/NOC/NIC. Metodologia: Trata-se de uma revisão de literatura, de pesquisa exploratória e bibliográfica. As informações referentes aos sinais e sintomas da doença foram obtidas por publicações indexadas nas bases de dados Literatura Latino-Americana e do Caribe em Ciências da Saúde (LILACS) e Scientific Eletronic Library Online (SciELO), seguindo os critérios de inclusão e exclusão. Resultados: Nota-se que as manifestações mais frequentes em casos leves e graves são coriza, dispneia, fadiga, febre, mialgia, obstrução nasal e tosse. De acordo com os achados clínicos foi desenvolvido um possível plano de cuidados para esses pacientes. Conclusão: Conclui-se que os profissionais de enfermagem compõem a linha de frente no combate e controle da propagação da infecção pelo novo coronavírus. Assim, possuem papel fundamental na assistência à saúde de pacientes e, por isso, necessitam realizar cuidados planejados e baseados em evidências.

Palavras-chave: Infecções por coronavirus; Diagnóstico de enfermagem; Resultados de enfermagem; Sinais e sintomas.

\begin{abstract}
Objective: The new coronavirus (COVID-19) belongs to a family of viruses that has a high mutation capacity in animals. SARS-CoV-2 follows the pattern of the most vulnerable individuals, such as the elderly and adults with chronic diseases, with the lowest number of victims, children. The present study aimed to identify the possible nursing diagnoses and present a care plan, through the application of the nursing process, to patients with mild and severe manifestations of COVID-19, using the NANDA/NOC/NIC taxonomy. Methodology: This is a literature review, exploratory and bibliographic research. Information regarding the signs and symptoms of the disease was obtained by publications indexed in the Databases Latin American and Caribbean Literature on Health Sciences (LILACS) and Scientific Electronic Library Online (SciELO), following the inclusion and exclusion criteria. Results: It is noted that the most frequent manifestations in mild and severe cases are runny nose, dyspnea, fatigue, fever, myalgia, nasal obstruction and cough. According to the clinical findings, a possible care plan was developed for these patients. Conclusion: It is concluded that nursing professionals compose the front line in combating and controlling the spread of infection by the new coronavirus. Thus, they play a fundamental role in patient health care and, therefore, need to perform planned and evidence-based care.
\end{abstract}

Keywords: Coronavirus infections; Nursing diagnosis; Nursing results; Signs and symptoms.

\title{
Resumen
}

Objetivo: El nuevo coronavirus (COVID-19) pertenece a una familia de virus que tiene una alta capacidad de mutación en animales. SARS-CoV-2 sigue el patrón de las personas más vulnerables, como los ancianos y los adultos con enfermedades crónicas, con el menor número de víctimas, los niños. El presente estudio tenía como objetivo identificar los posibles diagnósticos de enfermería y presentar un plan de atención, a través de la aplicación del proceso de lactancia, a pacientes con manifestaciones leves y graves de COVID-19, utilizando la taxonomía NANDA/NOC/NIC. Metodología: Se trata de una revisión bibliográfica, exploratoria y bibliográfica. La información sobre los signos y síntomas de la enfermedad se obtuvo mediante publicaciones indexadas en las Bases de Datos de Literatura Latinoamericana y del Caribe sobre Ciencias de la Salud (LILACS) y Biblioteca Electrónica Científica en Línea (SciELO), siguiendo los criterios de inclusión y exclusión. Resultados: Se observa que las manifestaciones más frecuentes en casos leves y graves son secreción nasal, disnea, fatiga, fiebre, mialgia, obstrucción nasal y tos. Según los hallazgos clínicos, se elaboró un posible plan de atención para estos pacientes. Conclusión: Se concluye que los profesionales de enfermería componen la primera línea en la lucha y el control de la propagación de la infección por el nuevo coronavirus. Por lo tanto, desempeñan un papel fundamental en la atención de la salud de los pacientes y, por lo tanto, necesitan realizar una atención planificada y basada en la evidencia.

Palabras clave: Infecciones por coronavirus; Diagnóstico de enfermería; Resultados de enfermería; Signos y síntomas.

\section{Introdução}

Os primeiros casos da atual infecção por coronavírus foram diagnosticados como pneumonia grave de etiologia desconhecida, com as primeiras ocorrências em 31 de dezembro de 2019 na cidade de Wuhan, China. Em seguida, as amostras respiratórias dos pacientes mostraram presença do novo coronavírus (SARS-CoV-2), identificado como agente responsável da doença COVID-19. Sua acelerada propagação em todo o mundo fez com que a Organização Mundial de Saúde (OMS) declarasse, em 11 de março de 2020, a infecção pela COVID-19 uma pandemia (Estevão, 2020).

O coronavírus é uma categoria de vírus que gera infecções respiratórias, contudo, como nunca se teve contato com o vírus antes, os seres humanos não apresentam imunidade. O vírus pode agir de forma leve no organismo, mas também pode causar infecção pulmonar grave. O período de incubação, que é o tempo em que a pessoa leva para apresentar os primeiros 
sintomas, pode ser de 2 a 14 dias. Sua transmissão se dá por inalação ou contato direto com gotículas infectadas, por meio de aperto de mão, gotículas de saliva, espirro, tosse, catarro e objetos/superfícies contaminadas (Brasil, 2020).

Os sintomas são inespecíficos e variados, sendo os mais comuns: coriza, dispneia, fadiga, febre, mialgia, obstrução nasal e tosse. Estima-se que cerca de $80 \%$ dos pacientes desenvolvam doença leve, $14 \%$ doença grave e 5\% doença crítica. Pacientes com doença grave geralmente mostram sinais e sintomas de pneumonia viral e podem progredir para situações como a Síndrome de Dificuldade Respiratória Aguda (SARA), insuficiência cardíaca aguda, lesão renal aguda, infecção, sepse ou choque (Estevão, 2020).

Destaca-se uma piora nos sintomas em pacientes de faixa etária entre 49 a 56 anos, idosos e portadores de doenças crônicas como diabetes e hipertensão, doenças pulmonares e pessoas com câncer. Dessa forma, esses pacientes estão particularmente mais propensos a desenvolverem casos graves e, consequentemente, necessitarem de tratamento em unidades de terapia intensiva (Carvalho et al., 2020).

Também há relatos de sintomas menos comuns e difíceis de mensurar de forma objetiva, como anosmia (perda do olfato), hiposmia (diminuição do olfato) e ageusia (perda do sentido do paladar) (Iser et al., 2020).

Segundo dados do Ministério da Saúde, até 10 de janeiro/2021, foram registrados no Brasil 7.873 .830 casos acumulados, sendo 63.000 casos novos, 7.036.530 recuperados e 638.326 em acompanhamento, com um total de óbitos de 198.974. A região com maior número de casos foi a região Sudeste com 2.771.288, seguida pela região Nordeste com 1.931.459 (Brasil, 2020).

O Brasil iniciou seu ciclo pandêmico em 22 de janeiro de 2020, quando teve seu primeiro caso suspeito, porém somente em 3 de fevereiro de 2020 declarou-se Emergência em Saúde Pública de Importância Nacional (ESPIN), por meio da Portaria MS n 188/2020, elaborando assim medidas de contingenciamento no país (Brasil, 2020).

A propagação da doença se desenvolveu de forma tão rápida que os serviços de saúde não conseguiram responder de forma satisfatória à pandemia. Além disso, o medo do desconhecido afetou drasticamente os profissionais de saúde que estavam na linha de frente. Nesse contexto, a enfermagem teve protagonismo fundamental na assistência aos pacientes, pois são tais profissionais os responsáveis pelos cuidados contínuos dos pacientes (Cofen, 2020).

Ao realizar a assistência ao paciente, o enfermeiro direciona o atendimento por meio do Processo de Enfermagem (PE), que norteia o cuidado individualizado e de acordo com a necessidade do paciente. Isso é realizado através da gerência do cuidado, do diagnóstico, planejamento, coordenação, organização, dimensionamento da equipe, execução e avaliação da assistência (Barros et al., 2020).

Diante disso, o estudo teve como objetivos identificar os possíveis diagnósticos de enfermagem, embasado na taxonomia North American Nursing Diagnosis Association (NANDA), do paciente acometidos pela COVID-19 e apresentar plano de cuidados para esses pacientes, seguindo as taxonomias Nursing Outcomes Classification (NOC) e Nursing Interventions Classification (NIC).

\section{Metodologia}

Trata-se de uma pesquisa exploratória e bibliográfica. A pesquisa exploratória é apropriada para os primeiros estágios da investigação, pode resultar em maior familiaridade, conhecimento e compreensão do fenômeno estudado entre o pesquisador e o tema pesquisado, visto que este ainda é pouco conhecido e explorado (Bersot, 2019). Já a pesquisa bibliográfica é uma fonte de informações, pois auxilia na atividade intelectual e contribui para o conhecimento cultural em todas as formas do saber. Ela se fundamenta em vários procedimentos metodológicos, desde a leitura até como fichar, organizar, arquivar e até no resumo do texto, sendo a base para as demais pesquisas (Fachin, 2017).

A estratégia de identificação e seleção de estudos foi a busca de publicações indexadas na base de dados: Literatura 
Latino-Americana e do Caribe em Ciências da Saúde (LILACS) e Scientific Eletronic Library Online (SciELO). A busca ocorreu por meio dos descritores "coronavírus" e "sinais e sintomas", associado ao termo booleano "AND".

Foram adotados os seguintes critérios de inclusão para seleção as publicações: artigos originais, de revisão e relato de experiência; manuais e protocolos; textos completos disponíveis e gratuitos; publicações nos idiomas português/inglês, publicados dentro do recorte temporal estabelecido (março/2020 a janeiro/2021). Foram excluídos os artigos apresentados em duplicidade, com acesso restrito e que não versavam adequadamente o conteúdo.

Após análise das principais manifestações clínicas apresentadas pelos pacientes da COVID-19, foram identificados os possíveis diagnósticos de enfermagem, embasados na taxonomia NANDA 2018-2020, e elaborado o plano de cuidados, a partir das taxonomias NOC e NIC.

\section{Resultados}

A identificação das publicações pré-selecionadas para esse estudo teve início com a realização do levantamento das publicações nas bases de dados descritas utilizando os descritores "coronavírus" AND "sings and syntoms". 
Figura 1 - Fluxograma das etapas de busca e seleção dos artigos.

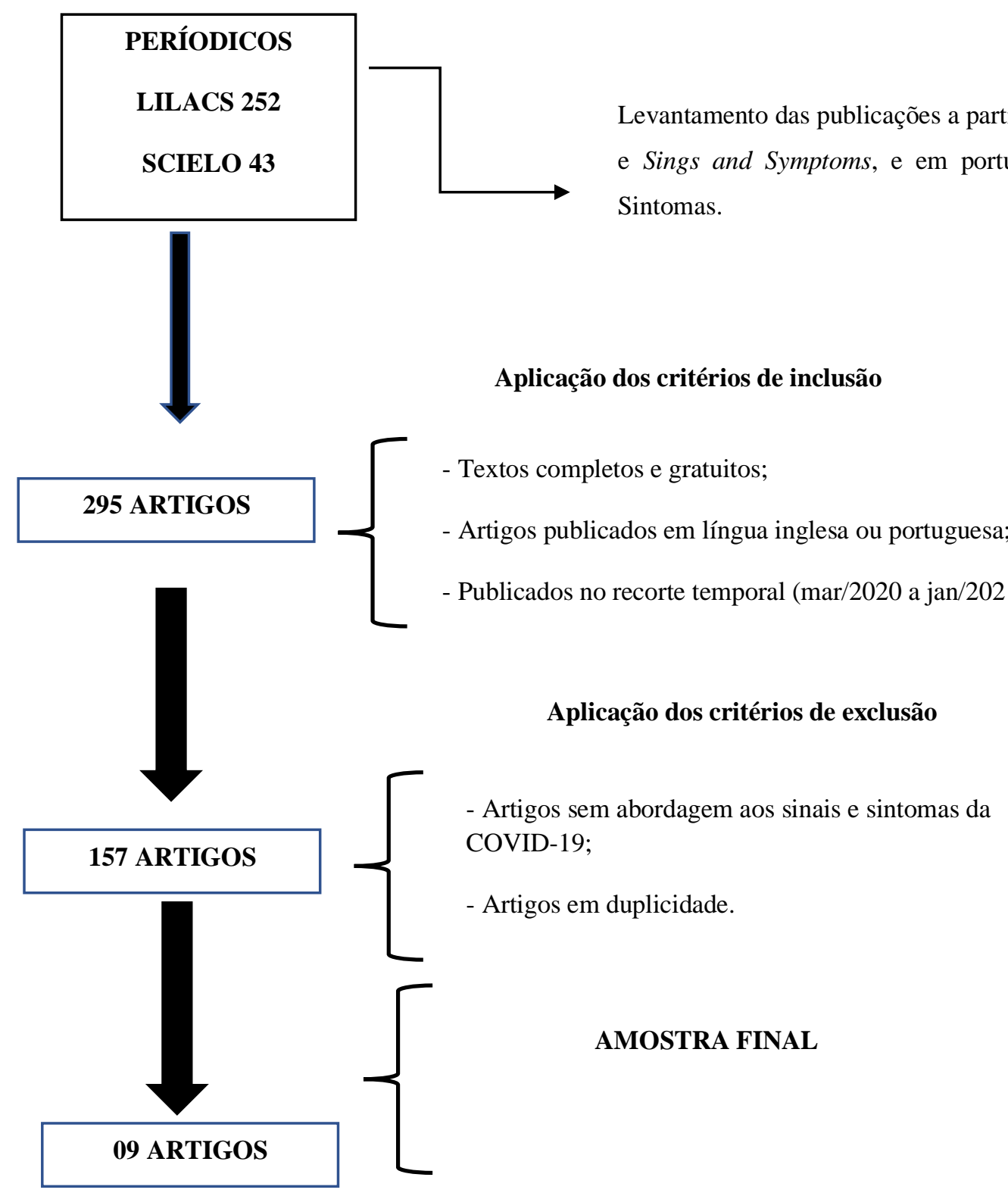

Fonte: Elaborado pelos autores.

Segundo a Figura 1, foram encontrados 295 artigos. Contudo, ao aplicar os critérios de inclusão, restaram 157 artigos. Em seguida, foram lidos os resumos para observar a abordagem temática de cada um. Após leitura, foram excluídos 148 artigos por não tratarem sobre as manifestações clínicas da COVID-19 ou por estarem em duplicidade. Assim, totalizou-se uma amostra final de 9 artigos (Figura 1), sendo 5 da base de dados SCIELO e 4 do LILACS (Quadro 1). 
Research, Society and Development, v. 10, n. 3, e6610313056, 2021

(CC BY 4.0) | ISSN 2525-3409 | DOI: http://dx.doi.org/10.33448/rsd-v10i3.13056

Quadro 1 - Amostra final da pesquisa bibliográfica, apresentando os sinais e sintomas nos casos leve e grave. Aracaju-SE, Brasil, 2021.

\begin{tabular}{|c|c|c|c|c|c|}
\hline $\begin{array}{l}\text { Mês/Ano da } \\
\text { Publicação }\end{array}$ & País & Autores & Base de Dados & Manifestações em casos leves & Manifestações em casos graves \\
\hline Fev/2020 & BRASIL & $\begin{array}{l}\text { CARVALHO } \\
\text { et al, } 2020\end{array}$ & SCIELO & Febre; Tosse; Dispneia; & SDRA; Infecção secundária; \\
\hline $\mathrm{Mar} / 2020$ & BRASIL & $\begin{array}{l}\text { ARAUJO et al, } \\
2020\end{array}$ & SCIELO & Cefaleia; Congestão nasal; Tosse; & Pneumonia; SDRA; Dispneia; \\
\hline Maio/2020 & BRASIL & $\begin{array}{l}\text { BRASIL, } \\
\text { 2020a }\end{array}$ & LILACS & Febre $(>=37,8 \mathrm{C}) ;$ Tosse; & $\begin{array}{l}\text { Dispneia; Mialgia; Fadiga; Diarreia; Choque } \\
\text { séptico; Diminuição do pulso periférico; }\end{array}$ \\
\hline Jun/2020 & BRASIL & $\begin{array}{l}\text { ISER et al, } \\
2020\end{array}$ & SCIELO & $\begin{array}{c}\text { Tosse; Fadiga; Mal-estar; Dispneia leve; } \\
\text { Cefaleia; Febre e Mialgia }\end{array}$ & SRAG; Pneumonia grave; \\
\hline Jun/2020 & BRASIL & $\begin{array}{l}\text { QUEIROZ et } \\
\text { al, } 2020\end{array}$ & $\overline{\text { LILACS }}$ & Tosse; Batimento de asa de nariz (dispneia) & SDRA; Pneumonia grave; \\
\hline Jun/2020 & BRASIL & $\begin{array}{l}\text { BRASIL, } \\
\text { 2020b }\end{array}$ & LILACS & $\begin{array}{l}\text { Tosse; Dor de garganta ou coriza; Diarreia; } \\
\text { Dor abdominal; Febre; Calafrio; }\end{array}$ & $\begin{array}{l}\text { Dispneia/Desconforto respiratório ou pressão } \\
\text { persistente no tórax ou Sat O2 <95\% em ar } \\
\text { ambiente (hipoxemia); }\end{array}$ \\
\hline Oct $/ 2020$ & BRASIL & $\begin{array}{l}\text { BARROS et } \\
\text { al, } 2020\end{array}$ & SCIELO & $\begin{array}{l}\text { Tosse; Congestão nasal; Fadiga; Coriza; } \\
\text { Diarreia; Anorexia; }\end{array}$ & Dispneia; Febre; Hipoxemia; SDRA; \\
\hline Nov/2020 & BRASIL & $\begin{array}{l}\text { NETO et al, } \\
2020\end{array}$ & SCIELO & $\begin{array}{l}\text { Tosse seca; Fadiga ou mialgia; Dispneia; } \\
\text { Febre; }\end{array}$ & SDRA; \\
\hline Dez/2020 & BRASIL & $\begin{array}{l}\text { HERMIDA et } \\
\text { al, } 2020\end{array}$ & LILACS & Tosse; Febre; Dispneia & SDRA; Taquipneia; Hipotensão; \\
\hline
\end{tabular}

Fonte: Elaborado pelos autores. 
De acordo com o Quadro 1, os estudos encontrados apresentaram pequenas divergência em relação às manifestações clínicas da COVID-19. Contudo, foi percebido que a tosse é um sinal característico da doença nos casos leves, sendo encontrada em $100 \%$ das publicações.

Os protocolos e manuais de conduta da COVID-19 do Ministério da Saúde informam que os principais sinais e sintomas apresentados em casos leves são: tosse, febre, dor de garganta, coriza, diarreia, dor abdominal e calafrio (Brasil, 2020a; Brasil, 2020b). Outros autores relatam que sintomas respiratórios também podem estar presentes, a exemplo da congestão nasal (Araujo et al., 2020; Barros et al., 2020) e dispneia (Carvalho et al., 2020; Iser et al., 2020; Queiroz et al., 2020; Neto et al., 2020; Hermida et al., 2020).

Em relação às manifestações clínicas apresentadas em casos grave da doença, observou-se que os problemas respiratórios estão presentes em todas as publicações, porém são apresentadas nas seguintes proporções: SDRA (78\%), dispneia (44\%), pneumonia (33\%), hipoxemia (22\%), fadiga (11\%) e taquipneia (11\%). Além dos distúrbios respiratórios, alguns autores relatam a presença de infecção secundária (Carvalho et al., 2020), mialgia (Brasil, 2020a), diarreia (Brasil, 2020a), choque séptico (Brasil, 2020a) e problemas relacionados à pressão arterial (Brasil, 2020a; Hermida et al., 2020). 
Quadro 2 - Processo de enfermagem (NANDA/NOC/NIC) aos casos leves da COVID-19, conforme manifestações clínicas encontradas na literatura. Aracaju-SE, Brasil, 2021.

\begin{tabular}{|c|c|c|c|}
\hline DIAGNÓSTICO DE ENFERMAGEM & $\begin{array}{l}\text { RESULTADOS } \\
\text { DE } \\
\text { ENFERMAGEM }\end{array}$ & $\begin{array}{l}\text { INTERVENÇÕES DE } \\
\text { ENFERMAGEM }\end{array}$ & PRESCRIÇÃO DE ENFERMAGEM \\
\hline $\begin{array}{l}\text { Desobstrução ineficaz das vias aéreas } \\
\text { relacionado a infecção respiratória } \\
\text { evidenciado por alteração da frequência } \\
\text { respiratória, alteração do padrão } \\
\text { respiratório, dispneia. }\end{array}$ & $\begin{array}{l}\text { Estado respiratório: } \\
\text { permeabilidade das } \\
\text { vias aéreas. }\end{array}$ & $\begin{array}{l}\text { Controle de vias aéreas; } \\
\text { Monitoração respiratória. }\end{array}$ & $\begin{array}{l}\text { Monitorar frequência, ritmo, profundidade e esforço das } \\
\text { respirações; } \\
\text { Inspecionar quanto a dispneia e eventos que melhorem ou piorem a } \\
\text { falta de ar. } \\
\text { Posicionar paciente para aliviar dispneia. }\end{array}$ \\
\hline $\begin{array}{l}\text { Deglutição prejudicada relacionada a } \\
\text { infecção evidenciado por dor de } \\
\text { garganta; }\end{array}$ & $\begin{array}{l}\text { Estado da } \\
\text { deglutição; }\end{array}$ & $\begin{array}{l}\text { Assistência no autocuidado: } \\
\text { alimentação; } \\
\text { Terapia da deglutição; }\end{array}$ & $\begin{array}{c}\text { Orientar o paciente a não conversar durante a alimentação; } \\
\text { Monitorar sinais e sintomas de aspiração; }\end{array}$ \\
\hline $\begin{array}{l}\text { Diarreia relacionada a infecção } \\
\text { evidenciado por dor abdominal; }\end{array}$ & Equilíbrio hídrico; & $\begin{array}{l}\text { Controle hídrico; } \\
\text { Controle da nutrição; }\end{array}$ & $\begin{array}{l}\text { Estimular quanto a gestão hídrica; } \\
\text { Avaliar sinais de desidratação; }\end{array}$ \\
\hline $\begin{array}{l}\text { Dor aguda relacionada a agente biológico } \\
\text { lesivo evidenciado por dor de garganta e } \\
\text { abdominal; }\end{array}$ & Controle da dor; & $\begin{array}{l}\text { Administração de analgésicos; } \\
\text { Controle da dor; }\end{array}$ & $\begin{array}{l}\text { Administrar analgésicos prescritos; } \\
\text { Avaliar escala da dor; }\end{array}$ \\
\hline $\begin{array}{l}\text { Hipertermia relacionada a COVID-19 } \\
\text { evidenciado por pele quente; }\end{array}$ & Termorregulação; & $\begin{array}{l}\text { Regulação da temperatura; } \\
\text { Monitorização dos sinais vitais; }\end{array}$ & $\begin{array}{l}\text { Monitorar temperatura corporal; } \\
\text { Administrar medicação antipirética, conforme necessário; } \\
\text { Aquecer o paciente; } \\
\text { Ofertar compressas com água fria; }\end{array}$ \\
\hline $\begin{array}{c}\text { Padrão respiratório ineficaz relacionado } \\
\text { a agente biológico lesivo evidenciado por } \\
\text { dispneia; }\end{array}$ & $\begin{array}{l}\text { Padrão respiratório: } \\
\text { ventilação, sinais } \\
\text { vitais; }\end{array}$ & $\begin{array}{l}\text { Controle de vias aéreas; } \\
\text { Assistência ventilatória; }\end{array}$ & $\begin{array}{c}\text { Avaliar expansibilidade pulmonar; } \\
\text { Monitorar frequência, ritmo, profundidade e esforços na respiração; }\end{array}$ \\
\hline $\begin{array}{l}\text { Risco de perfusão tissular periférica } \\
\text { ineficaz evidenciado por dispneia; }\end{array}$ & $\begin{array}{l}\text { Perfusão tissular: } \\
\text { Periférica; }\end{array}$ & Supervisão da pele; & $\begin{array}{l}\text { Monitorar cor e temperatura da pele; } \\
\text { Monitorar a pressão arterial, pulso, temperatura e estado }\end{array}$ \\
\hline
\end{tabular}




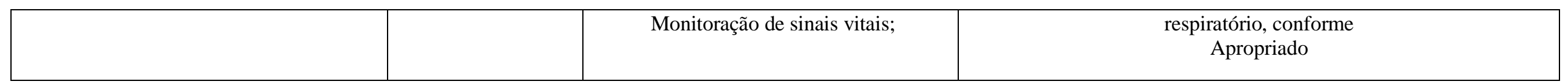

Fonte: Elaborado pelos autores.

A partir desses sinais e sintomas, foram identificados os possíveis diagnósticos de enfermagem e elaborado plano de cuidados para os pacientes com casos leves da COVID-19

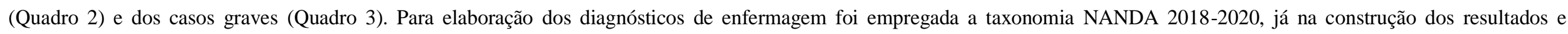
intervenções de enfermagem foram utilizados NOC e NIC, respectivamente.

Quadro 3 - Processo de enfermagem (NANDA/NOC/NIC) aos casos graves da COVID-19, conforme manifestações clínicas encontradas na literatura. Aracaju-SE, Brasil, 2021.

\begin{tabular}{|c|c|c|c|}
\hline $\begin{array}{l}\text { DIAGNÓSTICO DE } \\
\text { ENFERMAGEM }\end{array}$ & $\begin{array}{l}\text { RESULTADOS DE } \\
\text { ENFERMAGEM }\end{array}$ & $\begin{array}{l}\text { INTERVENÇÕES DE } \\
\text { ENFERMAGEM }\end{array}$ & PRESCRIÇÃO DE ENFERMAGEM \\
\hline $\begin{array}{l}\text { Débito cardíaco diminuído } \\
\text { slacionado a alteração na FC e no } \\
\text { ritmo cardíaco evidenciado por } \\
\text { alteração no ECG (assistolia, } \\
\text { AESP, TV, FV). }\end{array}$ & $\begin{array}{l}\text { Autocontrole de doença } \\
\text { cardíaca; }\end{array}$ & $\begin{array}{l}\text { Cuidados cardíacos; } \\
\text { Monitoração de sinais vitais. }\end{array}$ & $\begin{array}{l}\text { Monitorar o paciente física e psicologicamente de modo rotineiro; } \\
\text { Orientar o paciente quanto a importância de relatar imediatamente } \\
\text { qualquer desconforto torácico; } \\
\text { Mensurar Pressão Arterial, pulso, temperatura e o estado } \\
\text { respiratório. }\end{array}$ \\
\hline $\begin{array}{c}\text { iarreia relacionada a COVID-19 } \\
\text { evidenciada por dor abdominal, } \\
\text { evacuações de fezes líquidas, } \\
\text { cólicas. }\end{array}$ & $\begin{array}{c}\text { Função gastrointestinal; } \\
\text { Equilíbrio hídrico. }\end{array}$ & $\begin{array}{l}\text { Controle da diarreia; } \\
\text { Controle da nutrição; } \\
\text { Assistência no autocuidado; } \\
\text { Monitoração hídrica. }\end{array}$ & $\begin{array}{c}\text { Avaliar sinais de desidratação; } \\
\text { Registrar frequência e consistência das evacuações; } \\
\text { Estimular quanto a ingestão hídrica. }\end{array}$ \\
\hline $\begin{array}{l}\text { Jor aguda relacionada ao agente } \\
\text { ológico (coronavírus) evidenciada } \\
\text { sor autorrelato, expressão facial. }\end{array}$ & Controle da dor. & $\begin{array}{l}\text { Administração de analgésicos; } \\
\text { Controle da dor; } \\
\text { Apoio emocional; } \\
\text { Controle de medicamentos. }\end{array}$ & $\begin{array}{c}\text { Avaliar escala da dor; } \\
\text { Realizar controle da dor; } \\
\text { Administrar analgésicos prescritos. }\end{array}$ \\
\hline
\end{tabular}


Research, Society and Development, v. 10, n. 3, e6610313056, 2021

(CC BY 4.0) | ISSN 2525-3409 | DOI: http://dx.doi.org/10.33448/rsd-v10i3.13056

\begin{tabular}{|c|c|c|c|}
\hline $\begin{array}{l}\text { Fadiga relacionada à doença } \\
\text { (COVID-19) evidenciado por } \\
\text { apatia, cansaço e sonolência. }\end{array}$ & Bem-estar pessoal. & $\begin{array}{l}\text { Promoção do exercício; } \\
\text { Melhora do sono, terapia de } \\
\text { relaxamento; } \\
\text { Controle de energia. }\end{array}$ & $\begin{array}{c}\text { Manter o ambiente calmo e tranquilo; } \\
\text { Monitorar a ingestão nutricional para garantir recursos } \\
\text { energéticos adequados; } \\
\text { Evitar atividades de esforços. }\end{array}$ \\
\hline $\begin{array}{l}\text { Iipertermia relacionada à doença } \\
\text { _OVID-19) evidenciado por pele } \\
\text { quente e ruborizada. }\end{array}$ & Termorregulação & $\begin{array}{l}\text { Regulação da temperatura; } \\
\text { Tratamento da febre, proteção } \\
\text { contra infecção; } \\
\text { Monitoração dos sinais vitais. }\end{array}$ & $\begin{array}{l}\text { Administrar medicação antipirética, conforme necessário; } \\
\qquad \text { Monitorar temperatura corporal; } \\
\text { Realizar compressas com água em temperatura ambiente. }\end{array}$ \\
\hline $\begin{array}{l}\text { tolerância à atividade relacionada } \\
\text { a COVID- } 19 \text { evidenciada por } \\
\text { desequilíbrio entre a oferta e a } \\
\text { demanda de oxigênio. }\end{array}$ & Tolerância à atividade & $\begin{array}{c}\text { Controle de energia; } \\
\text { Monitoração respiratória }\end{array}$ & $\begin{array}{l}\text { Avaliar níveis de aptidão; } \\
\text { Monitorar resposta do paciente a cada atividade; } \\
\text { Encorajar a realização de atividade quando toleradas; }\end{array}$ \\
\hline $\begin{array}{l}\text { Padrão respiratório ineficaz } \\
\text { lacionado à fadiga da musculatura } \\
\text { respiratória evidenciado por } \\
\text { satimento de asa nasal, dispneia, } \\
\text { ıdrão respiratório anormal, uso da } \\
\quad \text { musculatura acessória. }\end{array}$ & $\begin{array}{c}\text { Padrão respiratório: } \\
\text { ventilação, sinais vitais. }\end{array}$ & $\begin{array}{l}\text { Controle de vias aéreas; } \\
\text { Assistência ventilatória; } \\
\text { Monitoração de sinais vitais. }\end{array}$ & $\begin{array}{l}\text { Monitorar frequência, ritmo, profundidade e esforços na } \\
\text { respiração; } \\
\text { Avaliar expansibilidade pulmonar; } \\
\text { Acompanhar a ocorrência de dispneia e eventos que possam } \\
\text { melhorar ou piorar o quadro do paciente; }\end{array}$ \\
\hline $\begin{array}{l}\text { Risco de choque evidenciado por } \\
\text { infecção respiratória. }\end{array}$ & Controle do risco & $\begin{array}{l}\text { Prevenção do choque; } \\
\text { Supervisão; Controle hídrico; } \\
\text { Monitoração e sinais vitais. }\end{array}$ & $\begin{array}{l}\text { Monitorar sinais de hipoperfusão tecidual; } \\
\text { Avaliar turgor da pele; } \\
\text { Verificar SSVV. }\end{array}$ \\
\hline $\begin{array}{l}\text { Risco de integridade de pele } \\
\text { prejudicada evidenciado por } \\
\text { hidratação, imunodeficiência, } \\
\text { nutrição inadequada. }\end{array}$ & Detecção de riscos & $\begin{array}{l}\text { Cuidados da pele; Prevenção de } \\
\text { lesão por pressão; Supervisão da } \\
\text { pele. }\end{array}$ & $\begin{array}{l}\text { Avaliar presença de sinais flogísticos (dor, calor, rubor, edema); } \\
\qquad \text { Realizar hidratação da pele; } \\
\text { Monitorar as possíveis modificações na pele. }\end{array}$ \\
\hline $\begin{array}{l}\text { Risco de função hepática } \\
\text { prejudicada evidenciado por }\end{array}$ & Controle de riscos & Controle de medicamentos; & Atentar para mudança de coloração da pele; \\
\hline
\end{tabular}


Research, Society and Development, v. 10, n. 3, e6610313056, 2021

(CC BY 4.0) | ISSN 2525-3409 | DOI: http://dx.doi.org/10.33448/rsd-v10i3.13056

\begin{tabular}{|c|c|c|c|}
\hline infecção viral. & & Avaliação da saúde & Orientar quanto ao uso correto e contínuo dos medicamentos; \\
\hline $\begin{array}{l}\text { Troca de gases prejudicada } \\
\text { relacionada a alterações na } \\
\text { membrana alveolocapilar } \\
\text { idenciada por diaforese, dispneia, } \\
\text { lipóxia, inquietação, taquicardia. }\end{array}$ & $\begin{array}{l}\text { Estado respiratório: troca } \\
\text { gasosa. }\end{array}$ & $\begin{array}{l}\text { Controle de vias aéreas; } \\
\text { Monitoração respiratória; } \\
\text { Controle de ácido básico; } \\
\text { Redução da ansiedade. }\end{array}$ & $\begin{array}{c}\text { Atentar para mudança na } \\
\text { coloração da pele, principalmente } \\
\text { cianose de extremidades; } \\
\text { Monitorizar a gasometria } \\
\text { arterial e a saturação de O2 por } \\
\text { oximetria capilar; } \\
\text { Avaliar padrão respiratório. }\end{array}$ \\
\hline $\begin{array}{l}\text { entilação espontânea prejudicada } \\
\text { slacionada a infecção respiratória } \\
\text { caracterizado por diminuição da } \\
\text { ressão parcial de oxigênio (PO2), } \\
\text { iminuição na saturação arterial de } \\
\text { igênio (SaO2), dispneia, aumento } \\
\text { i frequência cardíaca, aumento da } \\
\text { pressão parcial de dióxido de } \\
\text { carbono (PCO2). }\end{array}$ & $\begin{array}{l}\text { Estado respiratório: troca } \\
\text { gasosa, sinais vitais }\end{array}$ & $\begin{array}{l}\text { Monitoração respiratória; } \\
\text { Assistência respiratória. }\end{array}$ & $\begin{array}{l}\text { Manter cabeceira elevada } 30^{\circ} \text { a } 45 ; \\
\text { Manter vias aéreas desobstruídas; } \\
\text { Ofertar oxigênio, conforme necessidade. }\end{array}$ \\
\hline
\end{tabular}

Fonte: Elaborado pelos autores.

O Quadro 3, possui a finalidade de exibir os quadros mais graves da COVID-19, bem como a elaboração do processo de enfermagem em relação aos mesmos. 
Quadro 4 - Processo de enfermagem (NANDA/NOC/NIC) relacionado às situações emocionais e sociais da COVID-19. Aracaju-SE, Brasil, 2021.

\begin{tabular}{|c|c|c|c|}
\hline $\begin{array}{c}\text { DIAGNÓSTICO DE } \\
\text { ENFERMAGEM }\end{array}$ & $\begin{array}{l}\text { RESULTADOS DE } \\
\text { ENFERMAGEM }\end{array}$ & $\begin{array}{c}\text { INTERVENÇÃO DE } \\
\text { ENFERMÄGEM }\end{array}$ & PRESCRIÇÃO DE ENFERMAGEM \\
\hline $\begin{array}{l}\text { Ansiedade relacionada a COVID-19 } \\
\text { evidenciado por insônia, agonia, } \\
\text { incertezas, medo nervosismo, } \\
\text { alteração no padrão respiratório, } \\
\text { palpitações cardíacas. }\end{array}$ & Autocontrole da ansiedade & $\begin{array}{l}\text { - Redução da ansiedade; } \\
\text { - Técnica para acalmar; } \\
\text { - Terapia de relaxamento; } \\
\text { - Apoio emocional. }\end{array}$ & $\begin{array}{l}\text {-Esclarecer dúvidas do paciente em relação ao tratamento da } \\
\text { COVID-19; } \\
\text {-Estabelecer relação de confiança com o paciente; } \\
\text {-Relatar sobre o estado real de saúde do paciente. }\end{array}$ \\
\hline $\begin{array}{l}\text { Distúrbio no padrão de sono } \\
\text { relacionado ao padrão de sono não } \\
\text { restaurador evidenciado por } \\
\text { dificuldade para iniciar e manter o } \\
\text { sono. }\end{array}$ & Melhora no padrão do sono. & $\begin{array}{l}\text { - Melhora do sono; } \\
\text {-Controle do ambiente; } \\
\text {-Musicoterapia. }\end{array}$ & $\begin{array}{l}\text { - Discutir com o paciente as medidas de conforto, técnicas de } \\
\text { monitoramento do sono e as mudanças no estilo de vida; } \\
\text {-Verificar a existência de uma barreira viral. }\end{array}$ \\
\hline $\begin{array}{l}\text { Interação social prejudicada } \\
\text { relacionada a barreira de } \\
\text { comunicação evidenciada por função } \\
\text { social prejudicada. }\end{array}$ & Envolvimento social & $\begin{array}{l}\text {-Melhora da socialização; } \\
\text {-Escuta ativa; } \\
\text {-Redução do estresse por } \\
\text { mudança. }\end{array}$ & $\begin{array}{l}\text {-Favorecer o aumento da socialização por meio de redes } \\
\text { sociais e aplicativos de mensagens; } \\
\text {-Escutar ativamente; } \\
\text {-Explicar sobre as necessidades do isolamento social; }\end{array}$ \\
\hline $\begin{array}{l}\text { Isolamento social relacionado por } \\
\text { alteração no bem-estar (pandemia) } \\
\text { evidenciado por insegurança em } \\
\text { público. }\end{array}$ & Apoio social, envolvimento social. & $\begin{array}{l}\text {-Fortalecimento da } \\
\quad \text { autoestima; } \\
\text {-Apoio emocional; } \\
\text {-Aconselhamento. }\end{array}$ & $\begin{array}{l}\text {-Ofertar ambiente calmo e tranquilo; } \\
\text {-Orientar quanto as necessidades do isolamento para a sua } \\
\text { recuperação; } \\
\text {-Manter o isolamento social de familiares e amigos. }\end{array}$ \\
\hline $\begin{array}{l}\text { Medo relacionado ao cenário pouco } \\
\text { conhecido evidenciado por } \\
\text { apreensão, autossegurança } \\
\text { diminuída, gestos de inquietação, } \\
\text { dispneia. }\end{array}$ & Autocontrole do medo & $\begin{array}{l}\text {-Aumento da segurança; } \\
\text {-Apoio emocional; } \\
\text {-Melhora de enfrentamento; } \\
\text {-Aconselhamento. }\end{array}$ & $\begin{array}{l}\text {-Monitorar o estado emocional do indivíduo; } \\
\text {-Escutar atentamente, permitindo que o indivíduo expresse } \\
\text { seus sentimentos acerca dessa pandemia; } \\
\text {-Salientar a importância do isolamento social. }\end{array}$ \\
\hline
\end{tabular}


Research, Society and Development, v. 10, n. 3, e6610313056, 2021

(CC BY 4.0) | ISSN 2525-3409 | DOI: http://dx.doi.org/10.33448/rsd-v10i3.13056

\begin{tabular}{|c|c|c|c|}
\hline $\begin{array}{c}\text { Processos familiares interrompidos } \\
\text { relacionados a isolamento } \\
\text { evidenciado por mudanças na } \\
\text { interação com a comunidade; }\end{array}$ & Bem-estar da família; & $\begin{array}{c}\text { - Melhora no enfrentamento; } \\
\text { - Manutenção do processo } \\
\text { familiar; }\end{array}$ & - Proporcionar ações para melhorar o processo familiar; \\
\hline $\begin{array}{c}\text { Risco de síndrome do estresse por } \\
\text { mudança evidenciado por } \\
\text { isolamento social; }\end{array}$ & Enfrentamento; & - Escuta ativa; & - Estabelecer uma comunicação efetiva com o paciente; \\
& & & - Orientar sobre a necessidade do isolamento social; \\
\end{tabular}

Fonte: Elaborado pelos autores. 
Apesar da identificação desses diagnósticos relacionados aos sinais e sintomas da COVID-19, não se pode ignorar os problemas sociais e psíquicos em que muitos pacientes são acometidos, especialmente aqueles dos casos leves, que necessitam ficar em isolamento domiciliar. Pensando nisso, foram elaborados diagnósticos de enfermagem para essas situações especiais (Quadro 4).

\section{Discussão}

A utilização do processo de enfermagem ordena, prioritariamente, as necessidades de cada paciente, atribuindo um plano de cuidado eficaz baseado nos diagnósticos, resultados, intervenções e prescrições de enfermagem. Faz-se necessário sua implementação, visando a organização e execução de cuidados contínuos e de qualidade aos indivíduos infectados pelo coronavírus (Neto et al., 2020).

Todos os pacientes com COVID-19, suspeitos ou confirmados devem ser assistidos pela equipe de enfermagem através de ações desenvolvidas baseadas no processo de enfermagem. A tomada de decisão da equipe é baseada por meio do método científico, promovendo uma assistência segura, integral e individualizada, garantindo para o paciente um plano de cuidados de qualidade, encorajando o reconhecimento e a valorização da enfermagem (Queiroz et al., 2020).

A taxonomia NANDA desenvolve, aperfeiçoa e promove uma terminologia que reflete, com precisão, julgamentos clínicos de enfermeiros. Essa taxonomia apresenta os diagnósticos de risco, promoção da saúde e foco no problema (Bulechek, 2016).

Dentre os diagnósticos apresentados, observa-se a prevalência daqueles relacionados ao sistema respiratório. Segundo Maia (2020), a COVID-19 é caracterizada por afetar os pulmões e dessa forma, quando o vírus é inalado e chega a esse órgão, ocasiona uma inflamação e atinge os alvéolos, células responsáveis pela troca gasosa. Dessa forma, pode ocasionar diversos problemas respiratórios, como pneumonia ou até mesmo uma insuficiência grave respiratória.

Por se tratar de um processo infeccioso, verifica-se a presença frequente da hipertermia e dor aguda, em ambas as situações (casos leves e graves). Segundo Lima (2020), as pessoas com COVID-19 geralmente desenvolvem sinais e sintomas, incluindo febre persistente, em média de 5 a 6 dias após a infecção (período médio de incubação do vírus). Contudo, a febre pode não estar presente em alguns casos, especialmente em pacientes jovens, idosos e imunossuprimidos. Em outras situações ela pode ser mascarada pelo uso de medicamentos analgésicos que também possuem ação antitérmica.

A diarreia, diagnóstico presente em muitos casos, está relacionado a inflamação intestinal, no qual pode ocasionar desidratação ou perda de eletrólitos do corpo. O vírus SARS-CoV-2 aproveita a enzima conversora de angiotensina 2 (ECA2), como receptor para a sua entrada nas células. $\mathrm{O}$ vírus é arrastado pelo movimento mucociliar e pode ganhar o trato gastrintestinal. A ECA2 da mucosa intestinal está associada com o transportador de aminoácidos B0AT1 e regula a flora intestinal. Isso ocorre porque esse transportador permite a absorção de triptofano, que estimula a via mTOR a produzir peptídeos antimicrobianos. Assim, a infecção pelo SARS-CoV-2 altera a quantidade e bloqueia os receptores ECA2, causando deficiência de triptofano e menor produção de peptídeos antimicrobianos, podendo causar alteração do microbioma intestinal e inflamação (Almeida \& Chehter, 2020).

Dessa forma, nota-se que a COVID-19 não possui sintomatologia específica, como acontecem com outras doenças. Assim, é difícil realizar o diagnóstico apenas pela clínica, necessitando de exames específicos, a exemplo do RT-PCR (cadeia da polimerase com transcrição reversa em tempo real), considerado o "padrão-ouro" no diagnóstico. Por isso, o enfermeiro precisa compreender a fisiopatologia da doença e fazer uma avaliação minuciosa a fim de identificar a sintomatologia presente em cada paciente (Vieira et al., 2020).

Portanto, percebe-se a relevância do enfermeiro e da aplicação das etapas do processo de enfermagem (coleta de dados, diagnóstico de enfermagem, planejamento assistencial, implementação e avaliação) na qualidade do cuidado desse 
paciente (Sousa et al., 2020). Especialmente os pacientes com quadro respiratório comprometido, que podem evoluir para a gravidade de maneira rápida se não for estabelecido o tratamento precoce (Souza et al., 2020).

\section{Considerações Finais}

A COVID-19 é uma doença do novo século e por isso ainda existem muitas dúvidas a respeito de sua fisiopatologia. Suas manifestações clínicas não são fixas e por isso pode ser confundida com outras doenças, a exemplo da gripe e resfriado. O comportamento do vírus é diferente em cada organismo e tende a comprometer gravemente a saúde de idosos e pessoas com comorbidades crônicas.

A realização de uma avaliação detalhada do paciente é parte primordial do processo de assistência à saúde. Nesse sentido, o enfermeiro, ao aplicar o processo de enfermagem, tem a possibilidade de assistir o paciente de acordo com suas individualidades. O paciente com a COVID-19, doença com diversas especificidades, precisa de cuidado integral e individualizado, por isso a importância em realizar a assistência pautada no processo de enfermagem.

Sendo assim, faz-se necessário a realização de estudos futuros nessa temática, visto que os profissionais de enfermagem estão em todo o momento prestando assistência direta aos pacientes. Dessa forma, as evidências científicas auxiliarão os profissionais em um melhor atendimento e obtenção de um olhar integral aos pacientes.

\section{Referências}

Almeida, J. F. M. \& Chehter, E. Z. (2020). COVID-19 e o trato gastrintestinal: o que já sabemos? Einstein (São Paulo), 18, eRW5909. https://doi.org/10.31744/einstein_journal/2020RW5909

Araujo, L. F. S. C. Strina, A., Grassi, M. F. R., \& Teixeira, M. G. (2020). Aspectos clínicos e terapêuticos da infecção da COVID-19. Rede CoVida, 1-14.

Barros, A. L. B. L. Silva, V. M. Santana, R. F., Cavalcante, A. M. R. Z., Vitor, A. F., Lucena, A. de F., Napoleão, A. A., Lopes, C. T., Primo, C. C., Carmona, E. V., Duran, E. C. M., Butcher, H. K., Lopes, J. de L., Díaz, L. J. R., Cubas, M. R., Brandão, M. A. G., Lopes, M. V. de O., Nóbrega, M. M. L., Almeida, M. de A., \& Santos, V. B. (2020). Contribuições da rede de pesquisa em processo de enfermagem para assistência na pandemia de COVID-19. In Revista Brasileira de Enfermagem (Vol. 73, pp. 327-345). scielo.

Bersot, K. (2019). Pesquisa científica: a diferença entre exploratória, descritiva e explicativa. https://www.unasp.br/blog/pesquisa-cientifica-diferencas/.

Binsfeld, P. C., \& Colonello, N. A. (2020). Coronavírus -SARS-CoV-2: Classe de risco e consensos de biossegurança para laboratório com amostras infectantes. SciELO, 01-18.

Boletim epidemiológico diário. Ministério da Saúde. <https://www.saude.gov.br/images/pdf/2020/April/13/13.04.2020-APRESENTA\%C3\%87\%C3\%83O\%2 0COVID.pdf>.

Boletim Epidemiológico, Secretaria de Vigilância em Saúde, Ministério da Saúde. 2 COE No 02 Fev. $2020 .<$ https://portalarquivos2.saude.gov.br/i mages/pdf/2020/fevereiro/13/Boletim-epidemiologico-COEcorona-SVS-13fev20.pdf>.

Bulechek, G. M. (2016). Classificação das intervenções de enfermagem NIC: Elsevier.

Carvalho, A. P., Pimentel, A. M., Berezin, E. N., Coser, E., Rocha, M. A. W., \& Marques, S. R. (2020). Novo coronavírus (COVID-19). Sociedade Brasileira de Pediatria, 14, 1-12. https://www.sbp.com.br/fileadmin/user_upload/22340d-DocCientifico_-_Novo_coronavirus.pdf

Carvalho, A. R. V. S., Cezarotti Filho, M. L., Azevedo, P. C. P. de, Silveira Filho, R. N., Barbosa, F. T., Rocha, T. J. M., Sousa-Rodrigues, C. F., \& Ramos, F. W. S. (2020). Epidemiology, diagnosis, treatment, and future perspectives concerning SARS-COV-2: a review article. In Revista da Associação Médica Brasileira. 66, 370-374).

Cofen publica nota de esclarecimento sobre o Coronavírus (COVID-19). http://www.cofen.gov.br/cofen-publica-nota-de-esclarecimento-sobre-o-coronaviruscovid-19_77835.html>.

Costa, K. V. T., Carnaúba, A. T. L., Rocha, K. W., Andrade, K. C. L., Ferreira, S. M. S., \& Menezes, P. de L. (2020). Olfactory and taste disorders in COVID19: a systematic review. In Brazilian Journal of Otorhinolaryngology (Vol. 86, pp. 781-792). scielo .

Croda, J. H. R., \& Garcia, L. P. (2020). Resposta imediata da Vigilância em Saúde à epidemia da COVID-19. In Epidemiologia e Serviços de Saúde (Vol. 29). scielo.

Dantas, T. P., Alexandro, C., Teixeira, V. R., Roriston, R., Isabel, M., Rafael, L., Sampaio, L., \& Pinheiro, W. R. (2020). Diagnósticos de enfermagem para pacientes com COVID-19. Journal Health NPEPS, 5(1), 396-416. https://doi.org/http://dx.doi.org/10.30681/252610104575

Estevão, A. (2020). COVID -19. Acta Radiológica Portuguesa, 32(1), 5-6. 
Research, Society and Development, v. 10, n. 3, e6610313056, 2021

(CC BY 4.0) | ISSN 2525-3409 | DOI: http://dx.doi.org/10.33448/rsd-v10i3.13056

Fachin, O. (2017). Fundamentos da Metodologia Científica: noções básicas em pesquisa científica.

Garcez, R.M. (2020). Diagnósticos de enfermagem da NANDA-I: Artmed.

Gil. A.C. (2019). Como elaborar projetos de pesquisa: Atlas.

Hermida, P. M. V., Silveira, N. D., Bringhenti, L. J., Bugs, T. S., Miotto, P., Chiari, M. F., \& Sulis, P. M. (2020). Cuidados à pessoa suspeita de COVID-19 com sinais de gravidade na Atenção Primária à Saúde. Enfermagem Em Foco, 11(2), 192-198. https://doi.org/10.21675/2357-707x.2020.v11.n2.esp.4223

Iser, B. P. M., Sliva, I., Raymundo, V. T., Poleto, M. B., Schuelter-Trevisol, F., \& Bobinski, F. (2020). Definição de caso suspeito da COVID-19: uma revisão narrativa dos sinais e sintomas mais frequentes entre os casos confirmados. Epidemiologia e Serviços de Saúde, 29(3), e2020233.

Júnior, A. M. de M. (2020). Covid-19: calamidade pública. Medicus, 2(1), 1-6. https://doi.org/10.6008/cbpc2674-6484.2020.001.0001

Lima, C. M. A. de. (2020). Informações sobre o novo coronavírus (COVID-19). Colégio Brasileiro de Radiologia e Diagnóstico Por Imagem, 53(2), V-VI. https://doi.org/10.1056/NEJMoa2002032.5.

Maia, S. (2020). Como o pulmão é gravemente afetado pela COVID-19. https://www.saude.se.gov.br/pneumologista-explica-como-o-pulmao-e-gravementeafetado-pela-covid-19/>.

Ministério da Saúde. Coronavírus. 2020. https://coronavirus.saude.gov.br/.

Ministério da Saúde. Secretaria de Políticas de Saúde. Coronavírus (COVID-19). Brasília, DF, 2020. Recuperado de https://coronavirus.saude.gov.br/sobre-adoenca\#o-que-e-covid.

Moorhead, S. (2016). Classificação dos resultados de enfermagem NOC: Elsevier.

Neto, J. M. R., Viana, R. A. P. P., Franco, A. S., Prado, P. R., Gonçalves, F. A. F., \& Nóbrega, M. M. L. da. (2020). Diagnós ticos/resultados e intervenções de enfermagem para pacientes graves acometidos por Covid-19 e Sepse. Texto \& Contexto - Enfermagem, 29.

Orientações para manejo de pacientes com COVID-19. Ministério da Saúde. https://pesquisa.bvsalud.org/portal/resource/pt/biblio-1102259.

Protocolo de manejo clínico do Coronavírus (COVID-19) na atenção primária à saúde: versão 9. Ministério da Saúde. https://pesquisa.bvsalud.org/portal/resource/pt/biblio-1095920.

Queiroz, A. G. S., De Souza, R. Z., Sottocornola, S. F., Barbosa, S. J., Pinheiro, F. A., \& Souza, L. P. de. (2020). Diagnósticos de enfermagem segundo a taxonomia da NANDA internacional para sistematização da assistência de enfermagem a COVID-19. Journal of Health \& Biological Sciences, 8(1), 1. https://doi.org/10.12662/2317-3076jhbs.v8i1.3352.p1-6.2020

Sousa, A. R. de, Santos, G. L. A., Silva, R. S. da, \& Carvalho, E. S. de S. (2020). Reflexões sobre o Processo de Enfermagem no trabalho de enfermeiras frente à pandemia da COVID-19. Enfermagem Em Foco, 11(1), 62-67. https://doi.org/10.21675/2357-707x.2020.v11.n1.esp.3501

Souza, C. D. F. de, Leal, T. C., \& Santos, L. G. (2020). Doenças do Aparelho Circulatório em Indivíduos com COVID-19: Descrição do Perfil Clínico e Epidemiológico de 197 Óbitos. Arquivos Brasileiros de Cardiologia, 115(2), 281-283. https://doi.org/10.36660/abc.20200453

Vieira, L. M. F., Emery, E., \& Andriolo, A. (2020). COVID-19 - Diagnóstico laboratorial para os clínicos / COVID-19 - Laboratory Diagnosis for Clinicians. Escuela Paulista de Medicina de La Universidad Federal de São Paulo, São Paulo (SP), Brasil, 1-20. 